EPRA International Journal of Economic and Business Review-Peer Reviewed Journal

Volume - 9, Issue - 7, July 2021 | e-ISSN: 2347 - 9671| p- ISSN: 2349 - 0187

\title{
SKILL ACQUISITION AS A TOOL FOR POVERTY REDUCTION IN IBADAN NORTH LOCAL GOVERNMENT, OYO STATE, NIGERIA
}

\author{
${ }^{1 *}$ Adedapo AA, ${ }^{2}$ Demokun BO \\ Center for Entrepreneurship and Innovation, University of Ibadan, Ibadan, Nigeria
}

*Corresponding Author: Adedapo AA

\begin{abstract}
DOI No: 10.36713/epra7710

Article DOI URL:https://doi.org/10.36713/epra7710

With the rapid technological advancement, which the world is now witnessing, and the continuous transformation of the world economies through globalization, there is a great pressure than before in many countries to develop their vocational education system to meet their developmental needs. That is why it is important for schools to prepare and supply future worker with appropriate knowledge and skills to enhance their productivity and therefore promote economic growth. Skills acquisition has sometimes become a tool for addressing the economic, political and social stability of some nations. As a result of rising unemployment, lack of skilled workers, high dropout rate, and the changing demographic nature of the workforce, these have placed the issue of education reform agenda high in many countries. It will further enhance the education implementers to focus on possible policies that will encourage skills acquisition among the youths in Ibadan North local government. Skills acquisition helps youths develop a positive attitude towards work and labour helps youths to be self-reliant and independent. A skill-acquired man is a self-employed man. A self-employed person can never go hungry because the skill he acquired provides food for him/her on a daily basis. But one who lacks skill acquisition will find it difficult to be self-employed because he/she has nothing to offer. Skill acquisition program is perceived as one of the crucial element in enhancing self-employment and economic productivity. It is vital for educational institutions to provide the resources needed to teach skill acquisition in schools. It is significant for parents, educators and even the government to note the relevance of scholars studying this skills in school because it provides students with life skills to become productive entrepreneurs, as it breeds creative and innovative ideas. In the long run, it impacts on the economy will be tremendously felt and will also increase personal freedom.
\end{abstract}

\section{INTRODUCTION}

Skills acquisition is a process whereby a person acquires or learns a particular skill or type of behavior needed for business through training or education (Idoko, 2007, Ibru, 2009, Chukwunenye \& Igboke, 2011; Amadi, 2012) in order to identify and exploit entrepreneurial opportunity for self- employment (Samian and Buntat, 2012; Stohmeyer, 2007). It also helps entrepreneurs to acquire selfconfidence, self-esteem and participate in decisionmaking at household and community levels (Cheston and Kuhn, 2002; Rufai et al, 2013). Exploitation of entrepreneurial opportunity also depends on the entrepreneur's level of education, skills or knowledge acquired through training, work experience and 
social network (Shane, 2003; Shastri \& Sinha 2010). Skills training and tertiary education on one hand could lead to business opportunities and impact on skills acquisition (Gatewood et al, 2004, Emaikwu, 2011;). Training and/or education produce prior experience, which leads to preparedness for activity (Shane, 2003).

The awareness for skills acquisition training and supports in order to stimulate activity and reduce business failure have been increased among stakeholders in the industry, business and government of many countries because entrepreneurs could be born or made (Abdullah, 2009). Skills' training is also a vital source of developing human capital (Brana, 2008; Ikegwu et al, 2014). Rufai et al (2013) and Dasmani (2011) found that skills graduates could not get employment because they possessed low interpersonal relationship skills and low self-confidence required by industries since they were not introduced to formal education while in training.

However, numerous studies asserted that skills training and tertiary education could lead to activity or self-employment (Stohmeyer, 2007, Salman, 2009, Amadi, 2012). Skills acquisition training was found to have positive effect on entrepreneurial activity in Nigeria (Ebong and Asodike, 2011; Ekpe and Mat, 2012; Ibru, 2009; Ikegwu et al, 2014). Skills acquisition training was also found to have positive effect on the youth entrepreneurial activity. (Samian and Buntat, 2012). Skills acquisition is frequently perceived as the solution to improving the opportunities of youths who lack the resources, skills or motivation to continue with higher education. Many argued that skills acquisition provides useful skills to prepare for youths' entry into the labor force and improve their chances of a successful professional career (Quintini and Martin, 2006; OECD, 2010).

Beach (1990) opined that skill acquisition is the process of enlarging people's choice for a long and healthy life, knowledge acquisition, healthy life, knowledge acquisition for a decent standard of living. He went further to expatiate that it is freedom from economic, social and education and access and opportunities for being creative and productive; and enjoying personal self-respect and guaranteed human rights. The central concern of human development is the quality of peoples' lives, what they are capable of doing. Oluremi (2008), also buttress this point by saying that skill acquisition aims at transforming the human person so as to bring about his/her potentials and make him or her a leader, who will in turn inspires and empowers others to excel and articulate meaningful vision for the society.

The UNDP's Human Development Report (1990) defines people as the real wealth of a nation. It is through skill acquisition that creativity, initiative; capability, commitment and empowerment that true development can be achieved. Asante and
Opoku-Asare (1998) said skill acquisition means releasing human energy, it means providing an opportunity for people to make the maximum contribution to their own development and to the self-sustaining development of their communities. It is therefore glaring that the need to provide skills is very crucial and vital if poverty is to be reduced or eradicated. What then can motivate and empower the people to put in their best to achieve highest level of productivity and being useful? For Adedeji (1987) education, skill, technology, capital, levels of remuneration are no doubt important. Therefore in all ramification, developing the human person by providing skill is the real solution to greater part of our challenges especially it helps to reduce the poverty level.

Webster's Dictionary defines skill acquisition as developed or acquired ability. The skills acquisition which is a vital instrument of empowerment that seeks to provide the people with different skills, vocation and entrepreneurial ability like bead making, hat making, sewing, fashion designing, shoe making and making workers interested in their job and at the same perspective improving on their existing skills. Emeka (2011) stated there are things people can do to impact their generation, they can acquire skill. Skill acquisition is not left for the poor and middle class people. Even career women or professional woman and man as well as the youth can acquire these skills to make the versatile and self-sustaining and independent.

Skills acquisition can also be in areas of making detergents, odour controls used in toilets for mopping the floor and bathrooms, production of Izal, Rob, Soda soaps, basket caps, school bags and a whole lot of skills. Buwai (2004) emphasized that the eradication or reduction of poverty is one of the central of poverty is one of the central objectives of contemporary development policy. The International community and its determination to overcome poverty has been highlighted by the sustainable activities of the International Development Donors such as the United Nations (UN), The European Union (EU), the World bank, the International Monetary Fund etc. are all ready and ever since they have been empowering nations and people.

The concept of skill acquisition is aimed at fighting and reducing poverty level in Nigeria and in Oyo in particular. According to the United Nations Report (1999) Nigeria's Human Poverty Index was only $41.6 \%$, which placed the country among the twenty-five (25) poorest nations in the world. Additional data from the Federal Office of Statistics (1999) further indicated the life expectancy for Nigeria was fifty-one (51) years and so to combat this phenomenon is the concept of skill acquisition that will in no doubt reduce the poverty level in Nigeria and in Oyo State in particular. Various Governments have repeatedly asserted its determination to use skills development as the main 
vehicle for assisting poor youths to breakout of the poverty trap. The underlying assumption continues to be that the acquisition of skills supported by public funding is the positive answer to the problem of unemployment. The consequences of this phenomenon of poverty include states of powerlessness, helplessness, despair and thus the inability to protect oneself against economic, social and political discrimination and marginalization. Other factors are deprivation, lack of rights, vulnerability and exposure to risks, shocks and stress. The predicament may further lead to desperation which in turn produces violence, high rate of robbery, theft, thuggery and other deviant human behavioural tendencies.

Based on its multi-dimensional nature, poverty is usually perceived using different criteria. This accounts for the numerous attempts in defining poverty; each definition tries to capture the perception of the author or the poor as to what the term is. Narayan and Petesch (2002) succinctly posit that, "poverty also may look quite different, seen through the eyes of a poor man or a woman." This is reflected in the differences in the various definitions, as poverty is considered to be a relative term. Narayan et al (2000) captured the definition from the point of view of the poor in different countries in the following perspectives: "Poverty is humiliation, the sense of being dependent, and of being forced to accept rudeness, insults, and indifference when we seek help." Another of such views of the poor is that expressed by a poor man in Kenya in 1997 as reported by Narayan et al (2000) thus:

"Don't ask me what poverty is because you have met it outside my house. Look at the house and count the number of holes. Look at my utensils and the clothes that I am wearing. Look at everything and write what you see. What you see is poverty."

The above reflect just descriptions of a few of the various perceptions of poverty at least from the poor. Poverty could denote a state of deprivation as was captured by Nigeria's Federal Ministry of Economic Co-operation and Development (1992) as "not having enough to eat, a high rate of infant mortality, a low life expectancy, low educational opportunities, poor water, inadequate heath care, unfit housing and a lack of active participation in the decision making process". It could also denote "absence or lack of basic necessities of life" or "lack of command over basic consumption needs such as food, clothing and or shelter", "glaring defects in the economy, etc." as stated by Aluko (1975).

The attempts made at defining poverty as captured above could be referred to as mere outline of the features or characteristics of poverty. In buttressing the difficulties encountered in arriving at a common and generally accepted definition of poverty, Aboyade (1987) posits that there seems to be a general agreement that poverty is a difficult concept to handle, and that it is more easily recognized than defined. Even attempts made to categorize some specific areas at which poverty could be viewed are fraught with lack of agreement. For instance, the Organisation for Economic Cooperation and Development (OECD) Guideline on Poverty Reduction (2000) stressed that "an adequate concept of poverty should include all the most important areas in which people of either gender are deprived and perceived as incapacitated in different societies and local context. It should encompass the causal links between the core dimensions of poverty and the central importance of gender and environmentally sustainable development." It failed to define poverty. Rather, it listed "the core dimensions" a definition of poverty should cover to include: economic, human, political, socio-cultural and protective capabilities. On the other hand, Narayan et al (2000), in buttressing that poverty is multi- dimensional, say, "definitions of poverty and its causes vary by gender, age, culture, and other social and economic contexts." They defined poverty from such categories as: lack of voice, power, independence, well or ill being, regional, gender, etc.

Even poverty elements like lack of power and voice, are explained differently in various countries. A Ghanaian in 1995 as stated in Narayan et al (2000) explained poverty in the dimension of lack of power and voice thus, "you know 'good' but you cannot do 'good'. That is, such a person knows what should be done but has not got the means." In the same vein, an elderly poor man in Uganda, explained in his own words; "the forces of poverty and impoverishment are so powerful today. Governments or the big churches can only manage them. So we now feel somewhat helpless. It is the feeling of helplessness that is so painful, more painful than poverty itself'. Adopting categorization as a basis for defining poverty generates even more disagreements as to what constitutes poverty at different levels of society such as the individual, household, community, district and regional.

OECD (2000) states that dimensions and measures of poverty may be inconsistent, which complicates the task of identifying the poor. Lending credence to the divergent views on poverty definition, the World Bank (1999) states that "participatory studies have cumulatively shown that the poor also experience and understand their poverty in terms of a range of nonmaterial and intangible qualities such as insecurity, lack of dignity and status or a lack of power or opportunity." These qualities and characteristics of poverty differ markedly by social group and by geographical and political economic contexts. Furthermore, examining the definition of poverty from the dimension of material well being reveals yet other varying opinions. The case of a 10-year old child in Gabon in 1997 as stated in Narayan et al (2000) succinctly captures it thus:

"When I leave for school in the mornings I don't have any breakfast. At noon there is no lunch, 
in the evening I get a little supper, and that is not enough. So, when I see another child eating, I watch him, and if he doesn't give me something I think I'm going to die of hunger."

The perception of this Gabonese child is akin to the song one old woman claimed her siblings used to sing as a result of lack of food to eat. It is translated thus: "Give me the one I will eat in the afternoon, in the night I am ready to forego food, food, food." Material well being is always relative. While some perceive it in terms of ability to meet basic needs such as the provision of three square meals daily, as in the cases above, few perceive it from ability to educate one's children, provide clothing for the family and relatively comfortable shelter; yet, some perceive it from ability to respond to emergencies by falling back on ones' savings. The lack of these things is ordinarily perceived as illbeing and by extension, poverty. According to OECD (2000) "economic capability means the ability to earn an income, to consume and to have assets, which are all key to food security, material wellbeing and social status. These aspects are often raised by poor people, along with secure access to productive financial and physical resources: land, implements and animals, forests and fishing waters, credit and decent employment".

Expressing poverty from the gender dimensions, the World Bank (1999) states that "in some instances the gender dimensions of this powerlessness were articulated, with implications for both men and women, boys and girls. It went further to illustrate with one Ayekale Odogun in Nigeria where "poor households were seen to be characterized by the inability of men to fulfill their role as provider." According to OECD (2000) the "processes causing poverty affect men and women in different ways and degrees. Female poverty is more prevalent and typically more severe than male poverty." It stated further that women "suffer violence by men on a large scale. They are more likely to be illiterate as well as politically and socially excluded in their communities. Hence, abilities of women to overcome poverty are generally different from those of men". There is also genderelated 'time poverty'. According to OECD (2001), this refers to the lack of time for all the tasks imposed on women, for rest and for economic, social and political activities. It is an important additional burden, which in many societies is due to structural gender inequality - a disparity that has different meanings for women and men. It is necessary to view poverty from an all-inclusive perceptive to enable adequate and effective policies to be formulated and implemented.

In this vein, the World Bank Report of 1990 adopted a view of poverty that covered various aspects of deprivation as "encompassing not only material deprivation (measured by an appropriate concept of income or consumption) but also low achievements in education and health." Poverty can be categorized as either relative or absolute on one hand, while on another, it can be classified as permanent or transient. Aliyu (2003) explained absolute poverty to be "the condition where an individual or group of people are unable to satisfy their basic requirements for human survival in terms of education, health, housing, feeding employment, transportation, etc." Corroborating the above meaning of absolute poverty, Aboyade (1987) defined it thus: "the insufficient or total lack of necessities and facilities like food, housing, medical care, education, social and environmental service, consumer goods, recreational opportunities, neighbourhood amenities and transport facilities." It is a basic fact that what is considered poverty level in one country or community may well be the height of well-being in another. This therefore, infers that poverty may be seen in relative terms. Relative Poverty, according to Aliyu (2003) "is a situation where an individual or group of people can be said to have access to his/their basic needs, but is comparatively poor among persons or the generality of the community".

Lending credence to the fact that poverty may be more of a relative concept, Aboyade (1987) stated vividly that relative poverty occurs when "people are poverty-stricken when their incomes, even if adequate for survival, fall radically behind that of the community average, they cannot have what the larger community regard as the minimum necessary for decency, and they cannot wholly escape therefore the judgment of the larger community that they are indecent. They are degraded, for in the literal sense, they live outside the grades or categories which the community regards as acceptable."

Poverty may be viewed from the dimension of permanency or transience. This dimension differentiates poverty based on time or duration on one hand, and distribution as to widespread, individual or concentrated on the other hand. According to Aliyu (2003) several types of poverty may be distinguished depending on such factors as time or duration (long- or short-term or cyclical) if the poverty is widespread throughout a population, but the occurrence itself is of limited duration; and distribution (widespread, concentrated, individual) if it involves relatively permanent insufficiency of means to secure basic needs. The condition may be so general as to describe the average level of life in a society or it may be concentrated in relatively large groups in an otherwise prosperous society. There is no doubt that the attempts made above to define poverty have given inkling to the causes of poverty as will be discovered in the subsequent paragraphs. Despite these difficulties, there are 'compromise' definitions of poverty generally recognized and used by different people. It may be sufficient to take just the following three: 
The Central Bank of Nigeria (1999) views poverty as "a state where an individual is not able to cater adequately for his or her basic needs of food, clothing and shelter; is unable to meet social and economic obligations; lacks gainful employment, skills, assets and self-esteem; and has limited access to social and economic Infrastructure such as education, health, portable water, and sanitation; and consequently, has limited chance of advantage his or her welfare to the limit of his or her capabilities".

The World Bank (2000) utilized inductive approach to uncover dimension of poverty and therefore defined poverty using many indices. One of such definitions is that poverty is "the lack of what is necessary for material well-being especially food, but also housing, land, and other assets. In other words, poverty is the lack of multiple resources that leads to hunger and physical deprivation."

Nuhu (2002) defined poverty as a "condition of privation or want in which a poor individual is incapable of satisfying the minimum basic human needs in such areas as food, housing and clothing, to ensure a decent life or existence". There is also the non-material dimension to poverty, which is manifested in incapacities to participate fully in the political and socio cultural activities of one's community. Simply put, poverty is powerlessness.

Efforts made towards reducing poverty would be more effective if appropriate definition of the main issue - Poverty - is made. Most views of poverty on which institutional frameworks were established were based on myopic view of poverty. Poverty should be viewed, and rightly too, from a multidimensional point. The World Bank and all the International agencies concerned with this have indeed been stressing on the need to view poverty in this direction as it would enable a comprehensive approach rather than piecemeal or 'one-off'. The World Bank's opinion on sustainable poverty reduction programmes become most relevant for effective poverty alleviation programmes in Nigeria: "countries should invest in basic social services, promotion of efficient and sustainable distortions that prejudice the poor's interest". To lend credence to the World Bank's opinion, the FOS (1996:124) proffers, "sustainable poverty reduction anchored on three approaches: - policies that promote efficient growth and which make use of the poor's most abundant asset, labour; · public expenditure on institutions that provide equitable access to education, health care, and other social services. These should properly integrate social-safety net for the most vulnerable groups in the society e.g. old age, disabled and chronically poor rural dwellers; and stable macroeconomic policy environment is also considered very imperative and vital."

From various studies, mostly those conducted by the World Bank, it is clearly revealed that poverty reduction problems are not based on the correct identification of the poor. Worse still is that the poor hardly benefit from the programmes meant to reduce their poverty. Therefore, the poor should be involved in the design and most importantly in the implementation of any programme meant for them. Unfortunately, up till now the very first thing in poverty reduction efforts - Poverty Reduction Strategies Paper (PRSP) is just being articulated. It is yet to be concluded and adopted in Nigeria. To this effect, it is obvious that serious difficulties will continue to be experienced in implementing any meaningful poverty reduction programme in the Country until such an important position paper is properly articulated and adopted. Albeit, no matter how well intentioned any poverty reduction programme may be in Nigeria, the target beneficiaries will continue to lose until corruption is reduced to its barest minimum. In this paper one of the skills to be acquired is in "gele" making and it is with the view of helping to reduce poverty around us.

\section{GELE MAKING}

The gele is one of those fashion pieces that have weathered the test of time. Gele is the Yoruba term for a woman's headpiece that serves as a complementary and final adornment. The gele is often the same colour or colours as the rest of her outfit, in that sense it is as much a part of the outfit as the iro and buba. A traditional Yoruba attire is not complete without the gele in the way that royalty are not complete without their crown. It is believed that some cultures used head wraps/geles before the days of slavery so that men could show off their wealth and the level of their social status and so that women could prove that they were prosperous and spiritual.

The gele is a large rectangular cloth tied on a woman's head in a variety of fashions. The material used to make it is usually of a stiff, but flexible, nature, for example, ofi, aso-oke (thickly woven silk), brocade (cotton) and damask. The gele should cover the hair completely and must be tied at the back of the neck. A lot of modern-day ladies wear their geles with some of their hair showing, as covering the hair makes the outfit feel and look more traditional. It is said that the gele is used to showcase the facial beauty of the African woman and to take attention away from the body. Unlike a hat or fascinator, the gele often needs the assistance of another person to pull the one end of the material tightly as it is wrapped around the wearer's hair. Because of the amount of effort that goes into donning a gele, removing it intact and simply placing it on one's head when needed, has become a common practice. Besides the difficulty of wearing one, it can also cause a headache because it is often tied too tightly. And yet, the women continue to wear it with pride. It is a symbol of elegance, of maturity and of wealth. Young girls don't wear a gele with their outfit, so it is as much a symbol of the coming of age of a woman as it is an elaborate fashion statement. 
And it is more than wrapping the material round one's head. Today, the women of Nigeria are willing to pay more to learn how to tie a gele properly. A well tied gele will attract as much attention, if not more, than the outfit itself. The gele is worn for glamorous events such as weddings, birthdays, christening, inaugurations or even funerals, and the styles have become more and more elaborate. Some resemble blossoming flowers whilst others are more fan-like. Gele-tying is an art, and like every other art, its success depends on creativity and mastery. Though it is traditionally part of the Yoruba attire, you can now find other tribes wearing the gele as well, so that it has become a symbol of Nigeria, far more than a symbol of the Yorubas.

According to Gwin (2018), The Gele (African head wrap) dates back to centuries ago. Back then, it was a symbol of wealth, any woman wearing it would usually hail from a prestigious family. The headdress 'gele' turns a 'plain Jane' to an African princess instantly. The African headdress is a fashion statement, you make a statement each time you step out wearing it. It's part of our culture; we have a very rich heritage as Africans which we should be proud of. We need to showcase these African wraps to the outside world.The 'gele' is perfect for styling 'Iro and buba' ('Top and Wrapper') as it makes a major statement when tied perfect.

Tying the gele can be done with 'Aso-Oke' 'Sego Gele', Damask, Netted Aso-Oke and many more fabrics, they are chosen in standout colours that compliment the whole look. Gele is tied in different ways as some people love it; small, medium or extremely large/standout. The most flattering ones include the ones will carefully layered/arranged overlaps in front or at the side as the go with most face shapes. So let's check out the types of gele styles in Nigeria and how they are adorned:

\section{TYPES OF GELE}

Casual Gele - Gele comes in many different forms. The very casual ones are usually the ones made out of the same fabric as the outfit being worn. It can also be a regular polyester scarf or shawl that can sometimes be worn as an head-tie.
Couture Gele - These are Gele made for the fashion conscious, the fashionistas of the Nigerian and other African culture. In this category are the Grand Swiss, Super Jubilee, and Hayes Gele. There's even the Net Gele Head tie (a net-like, see through fabric gele).

These are imported gele made with the African woman and culture in mind. They are usually made in Switzerland and come in both solid colors, with designs or embroideries.

\section{Gele Aso-Oke}

These are Geles that are made specially for special occasions, such as, traditional weddings, milestone birthday, chieftaincy title celebrations, and other special occasion celebrations. Custom-made Geles are usually made with Aso-Oke, a woven fabric spurned by hand or machine on demand.

Custom Gele Aso-Oke: Custom made aso-oke geles are made to the specification of the buyer. The design, fabric consistency and color are followed in details. The result is usually a blend of colorful prints and patterns. These colorful print fabrics are then used to make the Gele and Shawl (that drapes over the shoulder, or around the waist), or into the complete outfit which consists of the Gele, Shawl, Buba, and Wrapper. The price of custom-made geles is usually more than the ready-made geles.

\section{Bling Gele}

In our contemporary time, modern Nigerian women have found countless new ways to accessorize the Gele itself. The newest trend is to add as much bling to the gele as it can take. Bling Gele is becoming popular among the fashionista who want to take the wearing of the Gele to another level. To bling the Gele, precious stones, beads, rhinestones, and sometimes silk flowers can be added to the Gele for a more glamorous appeal. Such Gele helps to set one apart where one is the celebrant of a special occasion, such as, a wedding, wedding anniversary, or a milestone birthday celebration. Bling Gele is gradually catching on as the design is currently available on High Metallic Net Shimmery Gele. These types gele are adorned with a layer of quality rhinestone trim, usually on the edge of the Gele.

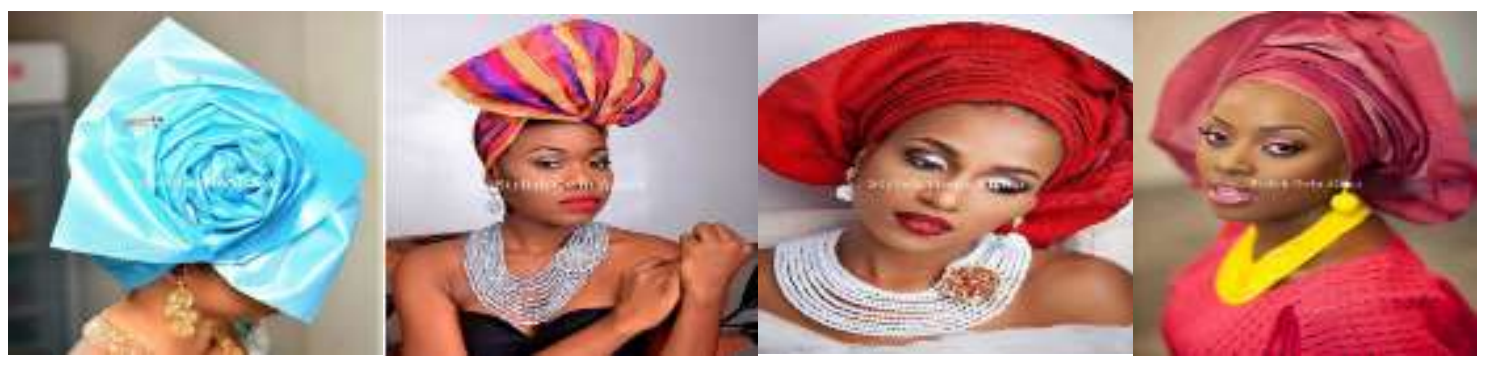

Figure 1: Different types of gele: Courtesy of Stylish Gwim Africana 
The broad purpose of this study is to investigate Gele making and skill acquisition as a tool for poverty reduction in Ibadan North local government. The specific purposes of the study are to:

1. Examine if lack of skill acquisition contributes to poverty in Ibadan North local government.

2. Determine how appropriate skill acquisition program can lead to poverty reduction in Ibadan North local government.

3. Examine the challenges to skill acquisition in Ibadan North local government.

4. Investigate if there is a difference in gender on the acquisition of skill in Ibadan North local government. 5. Find out if there are there adequate skill acquisition programmes in Ibadan North local government.

6 . Find out the relative and joint influence of gender, Educational status and marital status on skill acquisition among youths in Ibadan North local government.

7. Examine if a relationship exists between the skill acquisition and poverty reduction?

\section{METHODOLOGY}

\section{Research design}

The research adopted a survey method to actualize the objective of this study. Primary data was obtained through the use of a structured questionnaire. Questionnaire was designed solely to elicit primary data from youth.

\section{Area of study}

The study was conducted in Ibadan North local government, Ibadan, Nigeria. Ibadan North local government is the largest local government in Ibadan metropolis.

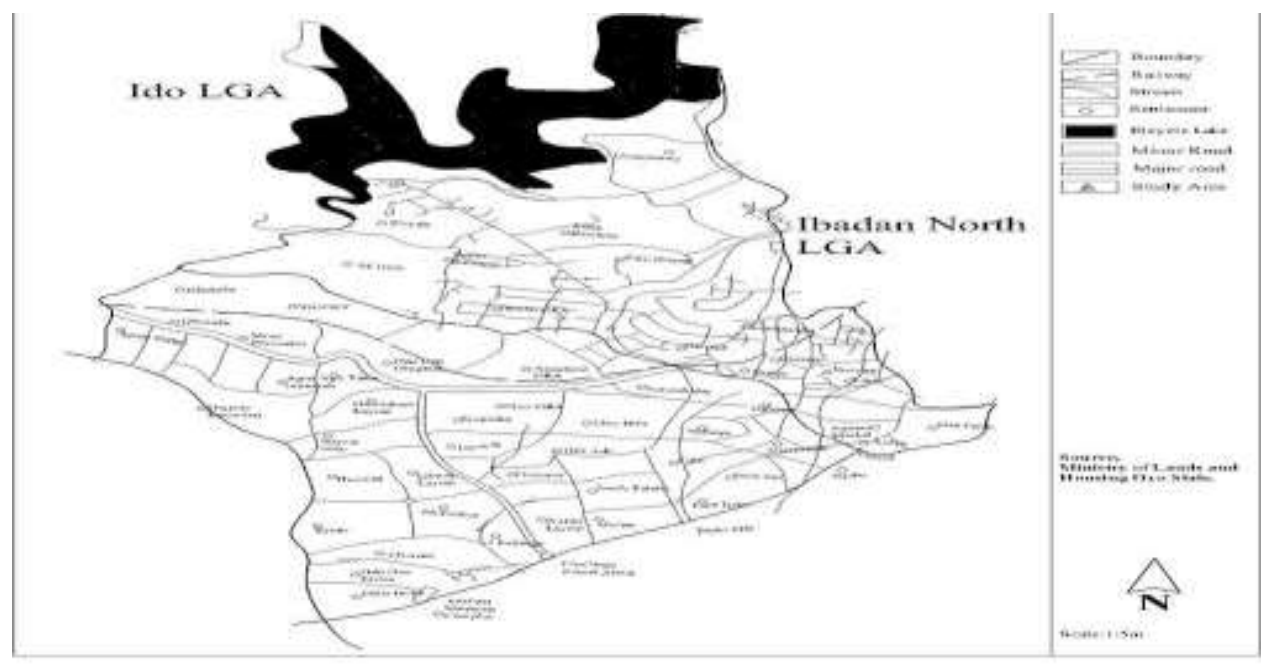

\section{Population and Sampling}

The study focused on youths within Ibadan North local government. The sample of the study was a total of 100 youths. The sampling technique used for this study was a simple random technique. The
Figure 2: Map of the areas under study

samples were stratified into the five (5) areas in Ibadan North. Twenty participants were selected at random from each of the five areas in the local government.

Table 1: Areas Under Study

\begin{tabular}{|c|c|}
\hline Areas & Sample Number \\
\hline Agbowo & 20 \\
\hline Sango & 20 \\
\hline Orogun & 20 \\
\hline Ajibode & 20 \\
\hline Bodija & 20 \\
\hline \multicolumn{2}{|c|}{ Total } \\
\hline
\end{tabular}

\section{Research Instrument}

The study employed a well-structured questionnaire in eliciting data from the study participant. The instrument contained over 30 items subdivided into five sections. Section A consisting socio demographic information of participants, Section B measured the perception of the respondent on skill acquisition contribution to poverty, section $\mathrm{C}$ measured the respondents perception on the challenges of skill acquisition, section D measured the skills acquired by the respondents, section $\mathrm{E}$ measured the expertise level of the respondent in gele making, section $\mathrm{F}$ tapped into perception of the respondent on gele making being a profitable skill 


\section{Method of Data collection}

Primary data were administered to the respondents at their various areas within the Ibadan North local government. The respondents were adequately briefed on the importance of the study; they were also assured of the confidentiality of their responses. The questionnaires were administered to randomly selected respondents from selected areas in Ibadan North.

\section{Method of Data Analysis}

The data collected through the questionnaires for the study was analyzed to determine the result of raised research questions and hypothesis. The data were analyzed using descriptive statistics such as frequency counts, simple percentage, t-test, Pearson Product Moment Correlation and multiple regression analysis.

\section{RESULTS}

Section A: Descriptive Analysis of sociodemographic information of participants

Analysis of Socio-Demographic information of Respondents

Table 2: Distribution of participant's gender

\begin{tabular}{|c|c|c|}
\hline Gender & Frequency & Percen \\
\hline Male & 32 & 32 \\
\hline Female & 68 & 68 \\
\hline Total & 100 & 100 \\
\hline
\end{tabular}

The above table indicates that a total of 100 people participated in the research out of which there were $32(32 \%)$ males and $68(68 \%)$ females.

Table 3: Distribution of participant's age

\begin{tabular}{|lll|}
\hline Age & Frequency & Percent \\
$10-20$ years & 18 & 18 \\
$21-30$ years & 70 & 70 \\
$31-40$ years & 12 & 12 \\
Total & $\mathbf{1 0 0}$ & $\mathbf{1 0 0}$ \\
\hline
\end{tabular}

The above table indicates that a total of 100 people participated in the research out of which $18(18 \%)$ were between the age of 10 and 20 years, $70(70 \%)$ were between the age of 21 and 30 years while 12 $(12 \%)$ were between the age of 31 and 40 years old.

Table 4: Distribution of participant's Religion

\begin{tabular}{|lll|}
\hline Religion & Frequency & Percent \\
Christianity & 70 & 70 \\
Islam & 30 & 30 \\
Total & $\mathbf{1 0 0}$ & $\mathbf{1 0 0}$ \\
\hline
\end{tabular}

The above table indicates that a total of 100 people participated in the research out of which there were $70(70 \%)$ Christians and 30(30\%) Moslems.

Table 5: Distribution of participant's employment status

\begin{tabular}{|lll|}
\hline Employment status & Frequency & Percent \\
Employed & 16 & 16 \\
Unemployed & 42 & 42 \\
Self employed & 42 & 42 \\
Total & $\mathbf{1 0 0}$ & $\mathbf{1 0 0}$ \\
\hline
\end{tabular}

The above table indicates that a total of 100 people participated in the research out of which $16(16 \%)$ are employed, 42(42\%) are unemployed and selfemployed each.

Table 6: Distribution of participant's education status

\begin{tabular}{lll}
\hline Education status & Frequency & Percent \\
No formal education & 4 & 4 \\
Primary & 6 & 6 \\
Secondary & 18 & 18 \\
Tertiary & 72 & 72 \\
Total & $\mathbf{1 0 0}$ & $\mathbf{1 0 0}$ \\
\hline
\end{tabular}


The above table indicates that a total of 100 people participated in the research out of which $72 \%$ have tertiary education, $18 \%$ secondary, $6 \%$ primary and $4 \%$ with no formal education.

Table 7: Distribution of participants' marital status

\begin{tabular}{|lll|}
\hline Marital status & Frequency & Percent \\
Single & 66 & 66 \\
Married & 32 & 32 \\
Divorced & 2 & 2 \\
Total & $\mathbf{1 0 0}$ & $\mathbf{1 0 0}$ \\
\hline
\end{tabular}

The above table indicates that a total of 100 people participated in the research out of which there were
$66(66 \%)$ are single, $32(32 \%)$ are married and $2(2 \%)$ are divorced.

\section{ANSWERING RESEARCH QUESTIONS}

Research Question 1: Will lack of skill acquisition contribute to poverty in Ibadan North local government?

Table 8: Participants response to research question 1

\begin{tabular}{|l|c|c|c|c|c|c|}
\hline Participants & SA & A & D & SD & MEAN & STD.DV \\
\hline $\begin{array}{l}\text { 1. Skill acquisition will contribute } \\
\text { to poverty reduction }\end{array}$ & $68(68 \%)$ & $14(14 \%)$ & $18(18 \%)$ & $0(0 \%)$ & 3.57 & .784 \\
\hline $\begin{array}{l}\text { 2. Skill acquisition will help youths } \\
\text { not to depend on white collar job }\end{array}$ & $62(62 \%)$ & $24(24 \%)$ & $14(14 \%)$ & $0(0 \%)$ & 3.48 & .731 \\
\hline $\begin{array}{l}\text { 3. Skill acquisition will help youths } \\
\text { to develop a positive attitude } \\
\text { towards work and labor }\end{array}$ & $52(52 \%)$ & $38(38 \%)$ & $10(10 \%)$ & $0(0 \%)$ & 3.42 & .669 \\
\hline $\begin{array}{l}\text { 4. Skill acquisition will help youth } \\
\text { to be self-reliant and independent }\end{array}$ & $64(64 \%)$ & $26(26 \%)$ & $10(10 \%)$ & $0(0 \%)$ & 3.54 & .673 \\
\hline $\begin{array}{l}\text { 5. Skill acquisition will help in the } \\
\text { reduction of crime rate in our } \\
\text { society }\end{array}$ & $50(50 \%)$ & $38(38 \%)$ & $12(12 \%)$ & $0(0 \%)$ & 3.38 & .692 \\
\hline
\end{tabular}

The mean result of 3.57 indicates that the participants agreed with item 1 that skill acquisition will contribute in the reduction of poverty, that of 3.48 indicates that the participants agreed with item 2 that skill acquisition will help youths not to depend on white-collar job, the mean of 3.42 indicates the participants agreed with item 3 that skill acquisition will help youths to develop a positive attitude towards work and labor, the mean of 3.54 indicates the participants agreed with item 4 that skill acquisition will help youth to be self-reliant and independent while the mean of 3.38 indicates the participants agreed with item 5 that skill acquisition will help in the reduction of crime in the society respectively. The average mean response is 3.47 .

Research Question 2: What are the challenges of skill acquisition in Ibadan North local government?

Table 9: Participants response to research question 2

\begin{tabular}{|l|l|l|}
\hline \multicolumn{1}{|c|}{ Challenges } & \multicolumn{1}{c|}{ Yes } & \multicolumn{1}{c|}{ No } \\
\hline The insufficient pay by the trainee is a problem of acquiring skills & $74(74 \%)$ & $26(26 \%)$ \\
\hline The hostile attitude of people towards the trainee & $72(72 \%)$ & $28(28 \%)$ \\
\hline $\begin{array}{l}\text { Inadequate equipment to start up a business discourages people } \\
\text { from acquiring a skill }\end{array}$ & $88(88 \%)$ & $12(12 \%)$ \\
\hline The lack of government support is a problem in acquiring skills & $62(62 \%)$ & $38(38 \%)$ \\
\hline Incompetency of the trainee is a problem in skills acquisition & $82(82 \%)$ & $18(18 \%)$ \\
\hline Absence of proper structure by the trainee to start up & $80(80 \%)$ & $20(20 \%)$ \\
\hline Lack of adequate training by the trainee & $78(78 \%)$ & $22(22 \%)$ \\
\hline Too many people doing engaging in the skill & $46(46 \%)$ & $54(54 \%)$ \\
\hline Cost of transportation on the part of the trainee. & $60(60 \%)$ & $40(40 \%)$ \\
\hline
\end{tabular}

Table above indicates that $74 \%$ of the participants stated that insufficient pay is a problem of acquiring skills, $72 \%$ stated that the challenge is the hostility of people towards trainees, $88 \%$ stated that inadequate equipment to start up is a challenge, $62 \%$ stated that the government lack of support is a challenge, $82 \%$ stated that incompetency on the part of the trainee is an issue, $80 \%$ stated absence of proper structure, $78 \%$ stated lack of adequate training by the trainee, $46 \%$ stated that many people are doing or engaging in the 
skill and $60 \%$ stated that the cost of transportation is a challenge in acquiring skills.

Research Question 3: What are the skills acquired among youths in Ibadan North local government?

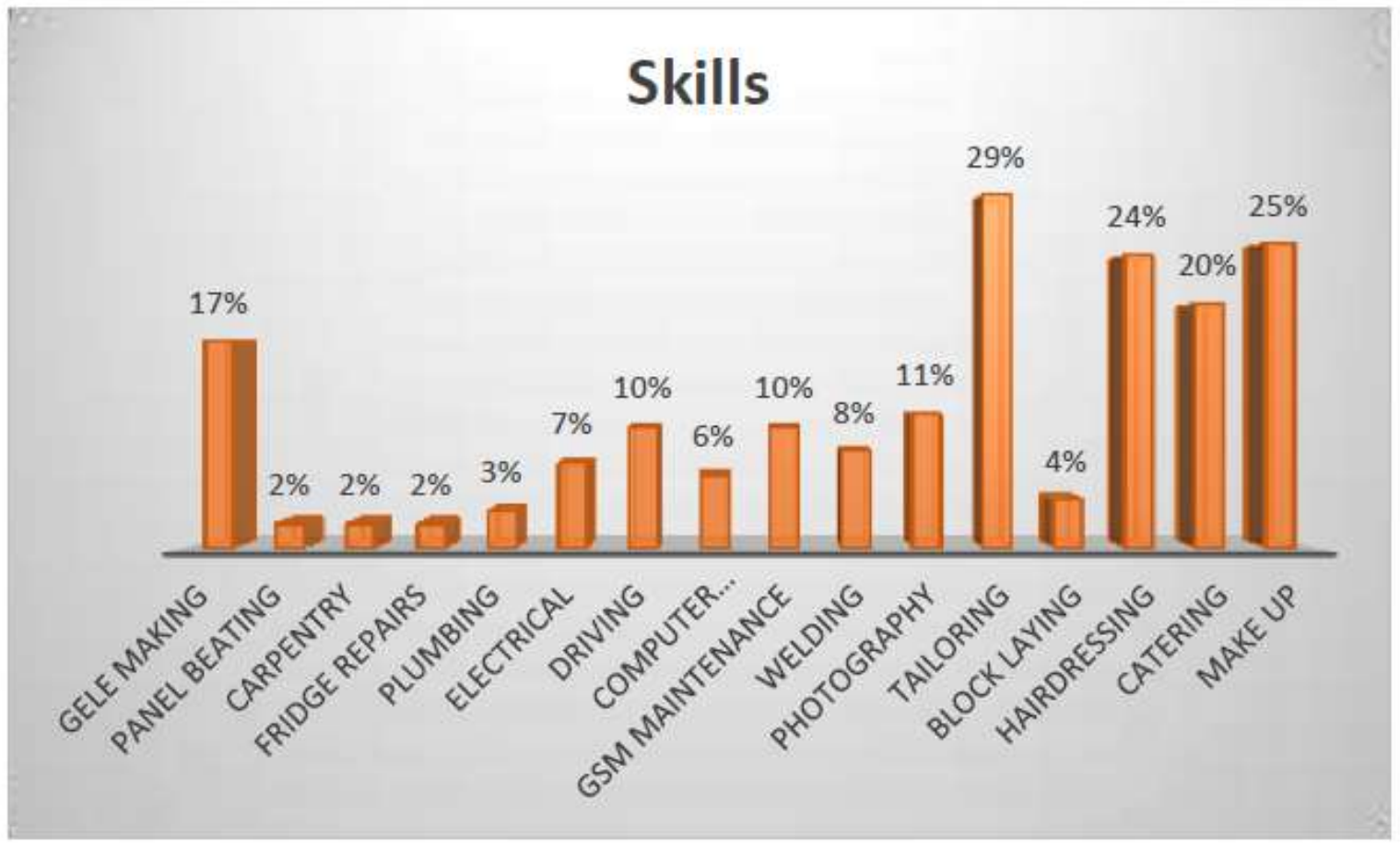

Figure 3: Participants response to Research Question 3

The highest number of participants was engaged in tailoring 29\%, hairdressing 24\%, makeover $25 \%$, gele making $17 \%$ among others.

Research Question 4: Can you make any type of gele?

Table 10: Participants response to research question 4

\begin{tabular}{|l|c|c|}
\hline \multicolumn{1}{|c|}{ Research question } & Yes & No \\
\hline Can you make any type of Gele? & $26(26 \%)$ & $74(74 \%)$ \\
\hline
\end{tabular}

The table above shows that $26 \%$ of the participants stated they can make any type of Gele while the remaining $74 \%$ stated not being able to make any type of Gele.

Research Question 5: What is the expertise level of youths in Gele making in Ibadan North local government?

Table 11: Participants response to research question 5

\begin{tabular}{|l|l|}
\hline Expertise Level & Frequency/Percentage \\
\hline Expert & $8(8 \%)$ \\
\hline Intermediate & $18(18 \%)$ \\
\hline Apprentice & $12(12 \%)$ \\
\hline Ignorant & $62(62 \%)$ \\
\hline
\end{tabular}

The table above shows that $8 \%$ of the participants are experts, $18 \%$ are intermediates, $12 \%$ are in the apprentice level while $62 \%$ are ignorant.

Research Question 6: Is Gele making a profitable skill that should be acquired by youths?

Table 12: Participants response to research question 6

\begin{tabular}{|l|c|c|}
\hline Research question & Yes & No \\
\hline $\begin{array}{l}\text { Is Gele making a profitable skill that should be acquired by } \\
\text { youths? }\end{array}$ & $90(90 \%)$ & $10(10 \%)$ \\
\hline
\end{tabular}

(c) 2021 EPRA JEBR | EPRA International Journal of Economic and Business Review ｜ www.eprajournals.com 
Table above shows that $90 \%$ of the participants stated Gele making is a profitable skill that should be acquired by youths while $10 \%$ did not agree is a profitable skill that should be acquired.
Testing the Hypothesis

Hypothesis one states that there is significant relationship between skill acquisition and poverty reduction. The hypothesis was tested using Pearson correlational analysis. The result is presented in table 13.

Table 13: Pearson Product Moment Correlation showing the relationship between skill acquisition and poverty reduction

\begin{tabular}{lllllll}
\hline Variables & Mean & $\begin{array}{l}\text { Std. } \\
\text { Deviation }\end{array}$ & N & r & P & Remark \\
\hline Skill acquisition & 29.14 & 3.00 & 100 & .202 & $<0.05$ & S \\
& & & & \\
$\begin{array}{l}\text { Poverty } \\
\text { Reduction }\end{array}$ & 17.32 & 2.99 & & & \\
\hline
\end{tabular}

The results obtained from the test are shown in table 4.13. The table shows that there was significant positive relationship between skill acquisition and poverty reduction at $(\mathrm{r}=-0.202 ; \mathrm{p}<05)$. The result implies that high skill acquisition significantly reduces poverty. The hypothesis is thus accepted.
Hypothesis two states that there is significant gender difference in skill acquisition among youths in Ibadan North local government. The hypothesis was tested using T-Test analysis. The result is presented in table 4.14.

Table 14: T-test showing gender differences in skill acquisition

\begin{tabular}{lllllllll} 
Variable & Gender & $\mathbf{N}$ & Mean & St. Dv & df & t & sig & P \\
\hline Skill & Male & 32 & 28.8125 & 3.01006 & 98 & -.745 & .580 & $>.05$ \\
acquisition & Female & 68 & 29.2941 & 3.01765 & & & & \\
\hline
\end{tabular}

Table 14 reveals that there was no significant difference in the skill acquisition of male and female; $\mathrm{t}_{(98)}=.580, \mathrm{p}>0.05$. Hence the hypothesis is rejected. Hypothesis three states that there will be significant joint and relative contribution of the socio demographic characteristics, skill acquisition and gele making on poverty reduction among youths in Ibadan North local government. The hypothesis was tested using multiple regression analysis. The result is presented in table 15 .

Table 15: Summary of multiple regression analysis showing the influence of gender, age, religion, employment, education, marital, skill acquisition and gele making on poverty reduction

\begin{tabular}{llllllll}
\hline Predictors & $\mathbf{B}$ & $\mathbf{T}$ & $\mathbf{P}$ & $\mathbf{R}$ & $\mathbf{R}^{2}$ & $\mathbf{F}$ & $\mathbf{P}$ \\
\hline Gender & -.179 & -2.108 & $<.05$ & 0.628 & 0.395 & 7.412 & $<.05$ \\
Age & -.460 & -4.517 & $<.05$ & & & & \\
Religion & -.051 & -.548 & $>.05$ & & & & \\
Employment & .250 & 2.758 & $<.05$ & & & \\
status & & & & & & \\
Marital status & .238 & 2.053 & $<.05$ & & &
\end{tabular}




$\begin{array}{llll}\text { Gele making } & .239 & 2.709 & <.05 \\ \text { Education } & .411 & 4.280 & <.05\end{array}$

The result revealed that the respondents gender, age, marital status, skill acquisition, gele making and education level jointly predicted poverty reduction $\left(\mathrm{R}^{2}=0.395\right.$, F $\left.(8,91)=7.412, \mathrm{p}<.05\right)$. When combined the respondents gender, age, marital status, skill acquisition, gele making and education level accounted for $39 \%$ of the change observed in poverty reduction. The result also revealed that gender $($ Beta $=-.179, \mathrm{t}=-2.108, \mathrm{P}<0.005)$, age $($ Beta $=-.460, \mathrm{t}=-4.517, \mathrm{P}<0.005)$, employment status $($ Beta $=.250, \mathrm{t}=2.758, \mathrm{P}<0.005)$, Marital status $($ Beta $=.238, t=2.053, \mathrm{P}<0.005)$, education $($ Beta $=$ $.411, \mathrm{t}=4.280, \mathrm{P}<0.005)$, Skill acquisition (Beta $=$
$.150, \mathrm{t}=1.637, \mathrm{P}<0.005)$ and gele making skill $($ Beta $=.239, \mathrm{t}=2.709, \mathrm{P}<0.005)$ have significant independent influence on poverty reduction while religion $($ Beta $=-.051, \mathrm{t}=-.548, \mathrm{P}>0.005)$ was found to have no independent significant influence on poverty reduction. The hypothesis was therefore accepted.

Hypothesis four states that there is a significant gender difference in Gele making among youths in Ibadan North local government. The hypothesis was tested using T-Test analysis. The result is presented in table 16 .

Table 16: T-test showing gender differences in gele making

\begin{tabular}{lllllllll} 
Variable & Gender & N & Mean & St. Dv & df & t & sig & P \\
\hline Gele & Male & 32 & 9.3750 & 3.38641 & 98 & .826 & .038 & $<.05$ \\
Making & Female & 68 & 8.8529 & 2.72229 & & & & \\
\hline
\end{tabular}

Table 16 reveals that there was a significant difference in gele making between male and female; $\mathrm{t}_{(98)}=.826, \mathrm{p}<0.05$. Hence the hypothesis is accepted.

\section{DISCUSSION, CONCLUSIONS AND RECOMMENDATIONS}

This chapter examines the research objectives formulated in relation to the research findings. The results of the findings are divided into three sections firstly the descriptive analysis result, correlation and regression analysis from hypothesis testing. The conclusions from the findings, recommendations, suggestions and contribution to knowledge are also indicated.

\section{DISCUSSION OF FINDINGS}

Based on the results presented in the previous chapter, we can deduce that majority of the participants perceive skill acquisition as contributing factor in the reduction of poverty in the society. The participant also depicted that skill acquisition will help youths not to depend on white-collar job. Also, the participants noted that skill acquisition would help youths to develop a positive attitude towards work and labor. This can be seen in table 8 research question 2, the mean of each item range between 3.38-3.57 which is equivalent to 'strongly agreed' according to the Likert scale rating. This simply indicate that majority of the participants perceive skill acquisitions as an essential tool in reducing poverty.

Table 9 reveals the challenges of skill acquisition as research question 2, "Inadequate equipment to start up a business" had the highest percentage compare to other items in the section as a major challenge in the acquisition of skills. This is however obvious from discussions of teeming youths looking for capitals to start a business. However, too many people engaging in the skill which was a challenge pointed out in the section had the least percentage of agreement as a challenge of skill acquisition.

Table 10 shows majority of the participants are engaged in certain skills either directly or indirectly as either primary or secondary means of sustainability. The percentage of the "acquired skills" is: tailoring (29\%), hairdressing (24\%), make-up $(25 \%)$, catering $(20 \%)$, gele-making $(17 \%)$ and other various kinds of skills. Also from the table, majority of the participants were engaged in tailoring as a skill and the least skill that they engaged themselves with is panel beating, carpentry and fridge repairs.

Table 11 depicted that $26 \%$ of the participants stated they could make any type of Gele while the remaining $74 \%$ stated not being able to make any type of Gele. Also their expertise level as reveal in table 12 shows that $62 \%$ are in the ignorant category, $12 \%$ are in the apprentice level, $18 \%$ in the intermediate level and just $8 \%$ are experts in gelemaking. Table 16 further reveals that $90 \%$ of the participants stated Gele making is a profitable skill that should be acquired by youths while $10 \%$ did not agree is a profitable skill that should be acquired.

\section{Discussion of Correlation, Regression Analysis and T-Test}

Table 13 shows that there was significant positive relationship between skill acquisition and poverty reduction. The implication of the result is that high skill acquisition will significantly reduce poverty in our society.

Table 14 reveals there was no significant difference in skill acquisition between male and female. The implication of this result is that while the 
male gender acquires skills, the female gender also acquires skills.

Table 15, which reveals the regression analysis shows that gender, age, marital status, skill acquisition, gele making and education level jointly, predicted poverty reduction at $39 \%$. From the independent contribution, gender contributed $17.9 \%$, age $46 \%$, employment status $25 \%$, marital status $23.8 \%$, education $41.1 \%$, skill acquisition $15 \%$ and gele making $23.9 \%$ to poverty reduction.

Table 16, which was analyzed using t-test, reveals there was a significant difference in gele making between male and female. This means that one of the gender is more engaged in gele making than the other gender.

\section{SUMMARY}

The contribution of youths to the economic development of any nation cannot be overemphasized and without youths a country future will be at a greater risk of losing it economically. As observed from findings, it is important youth acquire skills either formal or informal in order to cause a positive change in the society. The participation of youth in business either at large or small scale will cause a lasting change and reduction in poverty that has been ravishing the country since its inception.

Consequently, youths must engage in skill acquisition as a lasting solution to poverty in the country and it is however important for them to erase any negative mindset which can stand as a challenge from engaging or learning a skill. Getting the funds to start or learn a particular skill has been one of the problems stopping the Nigeria youths from indulging in skill acquisition.

Based on interpretation and result analysis in chapter four above, the following findings were discovered:

1. Firstly, it was found that quite a large number of participants agreed that skill acquisition is the only way to reduce poverty in the country.

2. In the opinion of the participants, inadequate equipment to start up a business or learn a skill is the major challenge in acquiring a skill.

3. The researcher observed that a large percentage of the participants are engaged in one skill or the other and the majority of them are into tailoring as a skill.

4. It was observed that very little percentage of the participants can make any type of gele as a skill of which majority of them are even in the ignorant level in gele making.

5. The participants stated that Gele making is a profitable skill that should be acquired by youths.

\section{CONCLUSION}

In conclusion therefore, the level of poverty in the country is as a result of unemployment coupled with lack of appropriate skills. That if there are no available jobs for the people, it will lead to poverty and anti-social behaviors. The challenges before Government is to establish skill acquisition schools for the people, while research institutions should be encouraged to research into possible solutions to poverty and joblessness.

\section{Contribution to Knowledge}

1. Gele making and skill acquisition as a tool for poverty reduction were established.

2. The importance of acquiring skills and the challenges involved was also documented.

\section{RECOMMENDATIONS}

1. Skill acquisition centres should be established by the Government at all levels.

2. Those who have no jobs should be encouraged so that they can be self-employed.

3. Special schools should be established that will teach skills acquisition.

4. Skill acquisition training should be introduced into our schools.

5. Soft loans should be introduced to assist the jobless to embark on self-help efforts.

6. Universities should make it mandatory in the aspect of skill acquisition to all students.

7. Orientation programmes should be organized to discourage youths from violent act in the society.

\section{SUGGESTIONS FOR FURTHER STUDIES}

The current study focused on Gele making and skill acquisition as a tool for poverty reduction in Ibadan North local government as a case study. Further study in this regard should focus on another skill using an experimental design method. There are other factors that can help solve the challenge of poverty reduction, which other researchers should look into this.

\section{REFERENCES}

1. Abdullah, S. H., Osman, M. H. \& Rahim, M. S. H. (2009). The Key Concept of Academic Technology Entrepreneurship in the Current Practice. Asia Pacific Journal of Innovation and Entrepreneurship, Korea Business Incubation Association, 2 (1), 77-96.

2. Aboyade, O. (1987), Integrated Economies: A Study of Developed Economies. London. Advisor Wesley Publishers. Achebe, C. (1998). The Trouble with Nigeria, Enugu Fourth Dimension Publishers.

3. Adedeji, A. (1987). An ecology for economic change. Challenge, 29(6), 4-8

4. Aliyu, A. (2003) Re-Structuring of the Poverty Alleviation Activities of the Federal Government of Nigeria National Poverty Eradication Programame Abuja.

5. Aluko, S (1975): "Poverty: Its Remedies in Poverty Alleviation in Nigeria. The Nigerian Economic Society, Ibadan

6. Amadi, B. O. (2012). Perceptions of Capacity Building Among Youths Involved in Vocational 
Skills Development. Journal of Social and Development Sciences, 3 (6), 214-222

7. Asante, E. A., \& Opoku-Asare, N. A. (2011). Cultural identity in the murals of Sirigu women and their role in art education and social sustainability. International Journal of Education through Art, 7(2), 187-202.

8. Beach, R. (1990). An Essay on Economic Theory, Auburn Alabama. Ludwig von Mises Institute ISBN 0-415-07577-7.

9. Brana, S. (2008). Microcredit in France: Does gender matter? 5th Annual Conference-Nice. European Microfinance Network

10. Buwai. S. (2004). Assessment of Administrative Management Processes Multinational Organizations in Nigeria: A Case Study of CocaCola Company, Nigeria, Enugu Plant (Doctoral dissertation).

11. Central Bank of Nigeria (1999) Nigeria's Development Prospects: Poverty Assessment And Alleviation Study Central Bank of Nigeria in Collaboration with the World Bank.

12. Cheston, S. \& Kuhn, L. (2002). Empowering women through microfinance. A case study of Sinapi Aba Trust, Ghana. USA: Opportunity International.

13. Chukwunenye, I. O. \& Igboke, B. N. (2011). Training, manpower development and job performance: Perception and relevance among civil servants in Ebonyi State of Nigeria. Journal of Economics and international Finance, 3 (6): 399-406

14. Dasmani, A. (2011). Challenges facing technical institutions graduates in practical skill acquisition in the upper east region of Ghana Asia-Pacific Journal of Corporative Education, Hamilton, New Zealand, 12 (2), 67-77

15. Ebong J.M. \& Asodike J.D. (2011). Skill Preferences of Participants of Skills Acquisition Programmes (SAPs) in Rivers State, Nigeria British Journal of Humanities and Social Sciences. 3(1).

16. Ekpe, I., Razak, C. R. \& Mat, N.(2012). Loan access, skill acquisition, bonding and the moderating effect of self-confidence on women entrepreneurs' business performance: A case of Nigeria. International Journal of Business and Management Studies, 4 (1): 77- 85.

17. Emaikwu, S. O. (2011). Integrating entrepreneurship skills acquisition in the university curriculum for national development. Journal of Research in Education and Society, 2(3), 40-48.

18. Emeka S. (2011) Women That Impact their Generation. Parluve Globalk Dimension, Enugu

19. Federal Office of Statistics (1996) SocioEconomic Profile of Nigeria 1996 FOS Lagos, 1996.

20. Federal Ministry for Economic Cooperation and Development. (1992) With Report On German Government Development Policy, Bonn.

21. Gatewood, E. J., Brush, C. G., Carter, N. M., Greene, P. G. \& Hart, M. M. (2004). Women entrepreneurs, growth and implications for the classroom. USA: Coleman Foundation whitepaper series for the USA Association for Small Business and Entrepreneurship.
22. Gwin, O. (2018). The Different types of Gele. Retrieved from https://blog.stylishgwinafrica.com/differenttypes-of-gele-styles/

23. Ibru, C. (2009). Growing microfinance through new technologies. Federal University of Technology, Akure, Nigeria.

24. Idoko, C. U. (2007). Skill acquisition and youth empowerment in Nigeria. Global Journal of Commerce \& Management Perspective, 3(1), 5154.

25. Ikegwu, E. M., Ajiboye, Y. O., Aromolaran, A. D., Ayodeji, A. A. \& Okorafor, U. (2014). Human empowerment through skill acquisition: Issues, impacts and consequences- A nonparametric view. Journal of Poverty, Investment and Development- An open access International Journal, 5 (1), 94-101.

26. Narayan, D. and Petesch P. (2002) Voices of the Poor: From Many Lands World Bank, New York.

27. Narayan, Deepa; Chambers, Robert; Shah, Meera K.; Petesch, Patti. 2000. Voices of the Poor: Crying Out for Change. New York: Oxford University Press for the World Bank. (C) World Bank.

https://openknowledge.worldbank.org/handle/10 986/13848 License: CC BY 3.0 IGO."

28. Nuhu, Y. (2002). As cited in An Assessment of Poverty Reduction Strategies in Nigeria (1983 2002). Abuja

29. Oluremi A. (2008): Fundamentals of Entrepreneurship, Quality Assurance and Corporate Governance. Journal of Business Management 4(6): $831-833$.

30. Organisation for Economic Co-operation and Development. (2001). Development Assistance Committee (DAC) Guidelines on Poverty Reduction" Policy Statement by the DAC on Poverty Reduction. Paris.

31. Quintini, G., \& Martin, S. (2006). Starting well or losing their way?: The position of youth in the labour market in OECD countries

32. Rufai, A., Abdulkadir, $M$ \& Abdul, B.(2013). Technical vocational education (TVE) institutions and industries partnership: Necessity for graduates' skills acquisition. International Journal of Scientific and Research Publications, $3(4), 1-4$.

33. Samian, S. S. \& Buntat, Y.(2012). Selfemployment: Perceptions among deaf students in Malaysian higher education through workplace experience. $3^{\text {rd }}$ International Conference on Business and Economic Research $\left(3^{\text {rd }}\right.$ ICBER 2012) Proceedings,pp.1545-1556, held on 12-13 March 2012 at Golden Flower Hotel, Bandung, Indonesia.

34. Salman, A. (2009). How to start a business: A guide for women. Pakistan: Center for International Private Enterprise, Institute of National Endowment for Democracy, affiliate of the USA Chamber of Commerce.

35. Shane, S. (2003). A general theory of entrepreneurship: The individual-opportunity nexus. UK: Edward Elgar.

36. Shastri, R. K. \& Sinha, A. (2010). The sociocultural and economic effect on the development 
of women entrepreneurs (with special reference to India). Asian Journal of Business Management , 2 (2), 30-34

37. Stohmeyer, R. (2007). Gender gap and segregation in self-employment: On the role of field of study and apprenticeship training. Germany: German Council for Social and Economic Data (RatSWD).

38. UNDP, U. (1990). Human development report. Chapter, 2, 22-25

39. United Nations Development Programme (2001) Nigerian Human Development Report 2000/2001 Millennium Edition. UNDP Lagos.

40. World Bank (1999). Nigerian Consultations with the Poor". Report of the Global Synthesis Workshop Septmember 22-23, 1999.

41. World Bank. (2000). World development report 2000/2001: Attacking poverty. The World Bank. 